\title{
Oxidative Stress and Antioxidant Treatment in Hypertension and the Associated Renal Damage
}

\author{
R. Davis Manning, Jr. Niu Tian Shumei Meng \\ Department of Physiology and Biophysics, University of Mississippi Medical Center Jackson, Jackson, Miss., USA
}

\author{
Key Words \\ Hypertension - Renal failure · Antioxidants • \\ Renal hemodynamics
}

\begin{abstract}
Reactive oxygen species (ROS) are elevated in humans with hypertension many of which develop end-stage renal disease (ESRD), and antioxidant capacity is decreased. About one-half of essential hypertensives have a salt-sensitive type of hypertension, and the amount of renal damage that occurs in salt-sensitive hypertensives greatly exceeds that of non-salt-sensitive hypertensives. Antioxidant therapy can improve cardiovascular outcomes in humans but only if sufficient doses are used. Salt-sensitive hypertensive animal models, especially Dahl salt-sensitive rats, have been used to investigate the relationship between hypertension, ROS and endstage renal damage. In experimental salt-sensitive hypertension, ROS increase and significant renal damage occur. In the Dahl salt-sensitive (S) rat on high $\mathrm{Na}$ for 3 weeks, renal damage is mild, renal levels of superoxide dismutase are decreased, and treatment with Tempol reduces arterial pressure. In the Dahl $\mathrm{S}$ rat on high $\mathrm{Na}$ for 5 weeks, renal damage is severe, GFR and renal plasma flow are decreased, and renal superoxide production is high. Treatment with vitamins $C$ and $E$ decreases renal superoxide production and renal damage and prevents the decrease in renal hemodynamics. Antioxidant treatment reduces arterial pressure, aortic superoxide pro-
\end{abstract}

duction and renal inflammation in DOCA-salt rats, and decreases blood pressure and aortic superoxide release and increases bioactive nitric oxide in SHR stroke-prone rats. In conclusion, in both human and experimental saltsensitive hypertension, superoxide production and renal damage are increased, antioxidant capacity is decreased, and antioxidant therapy can be helpful.

Copyright $(2005$ S. Karger AG, Basel

\section{Introduction}

The kidney is one of the major end organ targets of hypertension. The latest report from the US and Europe indicates that the prevalence of end-stage renal disease (ESRD) secondary to hypertension continues to multiply rapidly [1]. About one-half of essential hypertensives have a salt-sensitive type of hypertension, and both saltsensitive hypertensive patient and salt-sensitive animal models have shown that they are much more susceptible to renal damage than the non-salt-sensitive models of hypertension. However, the mechanisms of hypertension and the associated renal damage are not well known. One possible mechanism that is associated with hypertension and renal damage is oxidative stress. In this review, we present evidence from studies in humans and experimental animals that shows that oxidative stress is an important phenomenon that contributes to hypertension and links hypertension with ESRD.

\section{KARGER \\ Fax +4161306 1234 E-Mail karger@karger.ch} www.karger.com (c) 2005 S. Karger AG, Basel www.karger.com/ajn
R. Davis Manning, Jr., PhD

Department of Physiology and Biophysics

2500 North State Street

Jackson, MS 39216 (USA)

Tel. +1 601984 1813, Fax +1 601984 1817, E-Mail dmanning@physiology.umsmed.edu 
There is growing evidence that oxidative stress plays a major role in hypertension. Several studies have shown that induced oxidative stress can cause hypertension, oxidative stress increases in experimental hypertension, renal oxidative stress can cause renal damage, and reversal of oxidative stress with antioxidants decreases blood pressure. Studies supporting these findings will be presented in subsequent sections.

\section{Induction of Oxidative Stress Causes Hypertension}

Studies in which oxidative stress has been experimentally induced have caused increases in oxidative stress and hypertension. These results provide strong evidence for either an initiating or a sustaining role of ROS in hypertension.

Several studies have clearly shown that induction of oxidative stress with lead administration initiates hypertension. Lead enhanced both $\mathrm{O}_{2}^{-}$and hydroxyl radical production in cultured endothelial cells and intact animals [2-4]. Rats with increased lead in their drinking water experience an increase in ROS and nitrosylation of tyrosine in their blood vessels, and blood pressure increased [5]. Treatment with antioxidants lowered blood pressure and increased bioavailable nitric oxide [5].

Other evidence that showed that oxidative stress can cause hypertension has been provided in studies in which glutathione synthase was inhibited with buthionine sulfoximine (BSO) in the drinking water of rats. Arterial pressure and ROS increased as well as nitrotyrosine deposits in major organs, and nitric oxide (NO) metabolites in the urine decreased. When antioxidants were administered along with the BSO, the blood pressure increase was attenuated, tissue nitrotyrosine decreased, and NO in the urine increased $[6,7]$. Collectively, these data show that BSO-induced hypertension is mediated by increased ROS.

Transgenic rats also provide further evidence that induced oxidative stress can cause hypertension. In mice, deletion of the extracellular superoxide dismutase (SOD) gene caused increased oxidative stress and increased arterial pressure during low dose angiotensin II infusion [8]. On the other hand, transfer of the human extracellular SOD gene into SHR decreased their blood pressure [9]. Fibulin-5 binds extracellular SOD to vascular tissue, and deletion of the fibulin-5 gene raises the blood pressure of mice $[10,11]$. Therefore, changes in the key antioxidant SOD by gene manipulation change oxidative stress and blood pressure.
Studies in normotensive rats have shown that a high $\mathrm{Na}$ diet can significantly increase oxidative stress in spite of a lack of increase in arterial pressure. Arteriolar and venular $\mathrm{O}_{2}^{\overline{2}}$ production increased in Sprague-Dawley rats fed a high Na diet for 4-5 weeks [12]. Tempol + catalase or SOD + catalase decreased the $\mathrm{O}_{2}^{-}$production [12]. In these studies endothelium-dependent vasodilation was attenuated, and the mechanism by which $\mathrm{O}_{2}^{-}$causes endothelium dysfunction involves an inactivation of $\mathrm{NO}$ [13]. In normotensive Dahl $\mathrm{R}$ rats, a 3-week period of high $\mathrm{Na}$ intake caused an increase in urinary F2-isoprostane excretion [14]. However, neither renal medullary nor renal cortical $\mathrm{O}_{2}^{\bar{x}}$ production increased in these high $\mathrm{Na}$ Dahl $\mathrm{R}$ rats suggesting that an extrarenal source of $\mathrm{O}_{2}^{\overline{2}}$ production may be present.

One might wonder why the increases in $\mathrm{O}_{2}^{\bar{p}}$ production in the above studies on rats with a high $\mathrm{Na}$ diet did not increase arterial pressure, since many studies have indicated that increased $\mathrm{O}_{2}^{\bar{z}}$ production will cause hypertension. A recent study may give us the answer. In SpragueDawley rats that received a high $\mathrm{Na}$ diet for 8 weeks, which is much longer than the above-mentioned studies, the arterial pressure increased significantly, and urinary albumin excretion and renal inflammation increased [15]. It appears that hypertension develops slowly when $\mathrm{Na}$ intake is increased in normotensive rats, and the blood pressure elevations are paralleled by increases in ROS and renal damage. Therefore, long-term exposure to a high $\mathrm{Na}$ diet causes slow but progressive increases in oxidative stress, renal inflammation, and renal damage and arterial pressure.

\section{Oxidative Stress in Experimental Hypertension}

Further evidence that oxidative stress is plays a role in hypertension is provided by experimental hypertension studies. Increased oxidative stress has been found in the SHR, the stroke-prone SHR, DOCA-salt hypertension and the Dahl salt-sensitive rat [14, 16-20]. Different antioxidants in these studies reduced the elevated blood pressure indicating a role of oxidative stress in the etiology of the hypertension. However, in these models it is difficult to determine whether the oxidative stress is due to the high pressure or to other humoral, hormonal or genetic factors. A recent study has been helpful in dissecting out the effects of pressure and other factors on oxidative stress [21]. Rats received a suprarenal aortic band producing a coarctation and hypertension resulted. 
Therefore, the area above the coarctation was hypertensive and the area below was normotensive. ROS-mediated NO inactivation occurred in the high pressure area but not in the normotensive area, and NADPH oxidase increased in the hypertensive area of the aorta which may be a source of the increased $\mathrm{O}_{2}^{-}$production [22]. Therefore, studies reviewed thus far in this manuscript have shown that oxidative stress can cause hypertension, but also that hypertension can cause increased oxidative stress.

\section{Renal Oxidative Stress Can Cause Hypertension and Renal Damage}

Release of the superoxide anion in the kidney can have several deleterious effects. First, NO can be inactivated by $\mathrm{O}_{\overline{2}}^{\overline{2}}$. Since $\mathrm{NO}$ has several important renal actions such as prevention of tubular $\mathrm{Na}$ reabsorption and blunting of tubular glomerular feedback [23], inactivation of NO can result in excess $\mathrm{Na}$ reabsorption and enhanced TGF feedback and thus hypertension [24-26]. Inactivation of NO with $\mathrm{O}_{2}^{\overline{2}}$ forms peroxynitrite [27] which can nitrosylate tyrosine residues and thus cause tissue damage including renal damage.

In hypertensive models ROS production in the kidney has been evidenced by the presence of renal nitrotyrosine, considered to be a footprint of peroxynitrite. Those models with nitrotyrosine immunoreactivity are lead-induced hypertension [5], coarctation of the aorta [21], and the SHR [28]. In the Dahl salt-sensitive rat $\mathrm{O}_{2}^{-}$production from the renal cortical and medullary homogenates increases during high $\mathrm{Na}$ intake [14, 29], and Tempol administration lowers the $\mathrm{O}_{2}^{\overline{2}}$ production. Direct measurements of $\mathrm{H}_{2} \mathrm{O}_{2}$ from the renal interstitium have been made in rats with renal medullary SOD inhibition. These rats become hypertensive and Tempol + catalase infusion will prevent the increases in blood pressure [30]. This group also showed that direct infusion of $\mathrm{H}_{2} \mathrm{O}_{2}$ into the renal medullary interstitium causes hypertension. The Tempol administration in these rats increased the formation of $\mathrm{H}_{2} \mathrm{O}_{2}$, and the catalase metabolized the $\mathrm{H}_{2} \mathrm{O}_{2}$.

Other evidence for renal ROS during hypertension includes excretion of lipid peroxidation products. F2-isoprostane and malondialdehyde excretion increases in the SHR [16], in Dahl salt-sensitive hypertension [14, 31], in angiotensin II infusion [32], and in DOCA-salt hypertension $[18,19]$.

The mechanism by which renal ROS could cause hypertension has been studied by several investigators. Dur- ing acute infusion of Tempol in the SHR, arterial pressure and renal vascular resistance decreased [33]. This response was blocked by NO synthase inhibition but not by norepinephrine. This suggests that the inactivation of $\mathrm{NO}$ with $\mathrm{O}_{2}^{\overline{2}}$ may play an important role in this hypertension by increasing renal vascular resistance.

Inactivation of $\mathrm{NO}$ with $\mathrm{O}_{2}^{-}$in the thick ascending limb of Henle enhances Na reabsorption [34]. Studies have also shown that $\mathrm{O}_{2}^{\overline{2}}$ causes direct vasoconstriction in the renal cortical and medullary circulation $[35,36]$ and increases intracellular calcium in vascular smooth muscle and endothelial cells [37]. Isoprostanes also constrict the preglomerular vasculature [38]. Therefore, renal ROS not only cause renal vasoconstriction and $\mathrm{Na}$ retention but also renal damage as is described below.

\section{Renal Damage in Salt-Sensitive Hypertension}

During increases in blood pressure the experimental models of salt-insensitive hypertension that experience an increase in preglomerular resistance, such as the SHR, receive little renal damage. Yet the salt-sensitive hypertensive models experience significant and progressive renal damage. The likely difference is that in the salt-insensitive models, the increase in preglomerular resistance protects the glomerulus and distal vasculature from high pressures. Compared to the salt-insensitive models such as the SHR, the salt-sensitive models do not experience the increased preglomerular resistance which causes exposure of the glomerulus and distal vasculature to high pressures. These high intrarenal pressures may lead to significant oxidative stress, inflammation and renal damage.

Several studies have shown that a Dahl salt-sensitive (S) rat exposed to a high $\mathrm{Na}$ diet will experience severe renal damage. After 2-5 weeks on high Na intake the Dahl $S$ rats exhibit signs of significant renal damage associated with increased oxidative stress [14, 20,29, 31]. Early signs of renal damage include increases in urinary protein excretion $[14,20]$. Later, GFR and renal plasma flow, measured in conscious rats, decrease, and marked glomerular and vascular necrosis occur, and tubulo-interstitial damage is significant [29]. Left untreated these renal changes will rapidly progress to acute renal failure.

DOCA-salt rats also experience increased oxidative stress and show signs of renal inflammation. When DOCA-salt rats were treated with the antioxidant and NF-кB antagonist, pyrrolidinedithiocarbamate (PDTC) or the SOD mimetic, Tempol, significant decreases oc- 
curred in systolic blood pressure, aortic $\mathrm{O}_{2}^{-}$accumulation, renal monocyte/macrophage infiltration, and NF- $\mathrm{B}$ binding activity compared with untreated DOCA rats [19]. These results support an important role for oxidative stress in DOCA-salt hypertension, and the $\mathrm{O}_{2}^{-}$release in DOCA-salt rats is associated with a renal inflammatory response.

\section{Antioxidants Attenuate Renal Damage and Decrements in Renal Function in Salt-Sensitive Hypertension}

In the Dahl S rat a 3-week high Na diet decreases renal $\mathrm{Cu} / \mathrm{Zn}$ SOD and Mn SOD, which causes an increase in renal $\mathrm{O}_{2}$ production (SOD). The SOD mimetic, Tempol, reduces renal $\mathrm{O}_{\dot{2}}^{\bar{z}}$ production, renal damage and arterial pressure. However, renal damage in the Dahl $\mathrm{S}$ rat is much more severe after 5 weeks of a high $\mathrm{Na}$ diet, and the kidneys appear like those from patients with malignant hypertension. The renal damage that occurs in $\mathrm{S}$ rats on high $\mathrm{Na}$ includes renal interstitial damage, glomerular and arterial necrosis with thrombosed arteries and arterioles [29]. Treatment of rats with the antioxidants, vitamin $\mathrm{C}$ and $\mathrm{E}$ markedly reduced the renal damage. In addition, vitamins $\mathrm{C}$ and $\mathrm{E}$ prevented the pronounced decreases in GFR and renal plasma flow that occur in Dahl $\mathrm{S}$ rats on high $\mathrm{Na}$ for 5 weeks [29].

In Dahl S rats on high Na for 5 weeks, significant renal morphological damage occurred, and urinary protein excretion increased. Both renal structural damage and urinary protein excretion decreased when the high $\mathrm{Na} \mathrm{S}$ rats were treated with vitamins C and E [29]. In the past, many investigators believed that the renal damage in hypertension was directly due to exposure of the kidney to high pressures. However, oxidative stress markedly increased in high $\mathrm{Na}$ Dahl $\mathrm{S}$ rats, and scavenging of the free radicals with vitamins $\mathrm{C}$ and $\mathrm{E}$ reduced the renal damage even though mean arterial pressure only decreased $20 \mathrm{~mm} \mathrm{Hg}$. In particular, the superoxide release from the renal cortex and medulla in the high $\mathrm{Na}$ Dahl rats was significantly decreased in vitamin-treated rats, and this was associated with a reduction in renal damage. These data indicate that renal oxidative stress plays an important role in the hypertension and the associated renal damage in high $\mathrm{Na}$ Dahl $\mathrm{S}$ rats. However, one cannot preclude the possibility that the decrease in arterial pressure caused a reduction in renal damage.

There are several possible explanations for the GFR and renal plasma flow decreases in Dahl salt-sensitive rats during high $\mathrm{Na}$ intake. First, glomerular necrosis and interstitial damage occurred in high $\mathrm{Na} \mathrm{S}$ rats, and we have also reported that vascular necrosis was present [29]. A decrease in the number of functional nephrons with its associated vasculature could thus occur, and by this means GFR and renal plasma flow would decrease. Second, salt-sensitive hypertension has been associated with an increase in vasoconstrictor release. We have shown that F2-isoprostanes are released in Dahl S rats on high $\mathrm{Na}$ intake [14], and these isoprostanes can act as vasoconstrictors [14].

Increased intrarenal angiotensin II has also been reported during a high $\mathrm{Na}$ diet [39], and this can also result in renal vasoconstriction. Third, increased renal $\mathrm{O}_{2}^{\overline{2}}$ release inactivates nitric oxide thus decreasing renal vasodilation which is equivalent to increased vasoconstriction. This would cause decreases in cGMP as has been reported in Dahl S rats on high $\mathrm{Na}$ [31].

Other salt-sensitive models have responded favorably to treatment with antioxidants. In DOCA-salt rats, treatment with antioxidants PDTC or Tempol decreased arterial pressure, vascular $\mathrm{O}_{2}^{\bar{z}}$ production and renal infiltration of immune cells [19]. In the SHRSP, Tempol or vitamins $\mathrm{C}$ and $\mathrm{E}$ reduced oxidative stress and prevented progression of hypertension [40].

\section{Oxidative Stress in Human End-Stage Renal Disease}

In ERSD patients the antioxidant-pro-oxidant balance is shifted toward an increased oxidative stress. Several antioxidant systems have been shown to be deficient in patients with chronic renal insufficiency. Reduced levels of vitamin $\mathrm{C}$ are present, in part due to a dietary restriction of fresh fruits and vegetables to avoid hyperkalemia, and vitamin E intracellular levels are low, selenium levels are reduced, and there is a deficiency in the glutathione system [41, 42]. The imbalance in pro- and anti-oxidant capacities in these patients results in excess production of ROS in the blood [43], and neutrophils in uremic patients produce more ROS when stimulated.

The oxidant stress in dialysis patients causes increases in malondialdehyde, oxidized LDL, and increases in antibodies against oxidized LDL [44]. Oxidative stress in renal failure has been associated with hypertension [45, 46] endothelial dysfunction [47], decreased erythrocyte lifespan [48-51], and atherosclerosis and inflammation [52]. 


\section{Oxidative Stress in Human Hypertension}

Hypertension is a significant and independent risk factor for renal damage [53], especially in patients with saltsensitive hypertension, and there is a strong association between hypertension and oxidative stress. Several studies have shown that humans with essential hypertension have a decreased antioxidant capacity [54-57] and release increased amounts of ROS [58, 59]. SOD activity in erythrocytes is decreased in essential hypertensive patients $[57,60]$ and vitamin E levels are also reduced [60]. $\mathrm{O}_{2}^{\overline{2}}$ and $\mathrm{H}_{2} \mathrm{O}_{2}$ released by leukocytes and plasma concentrations of lipid peroxides increased in hypertensive patients whose blood pressure was not controlled [57]. Antihypertensive therapy in these patients decreased free radical production and lipid peroxides to normal [59].

More than one-half of essential hypertensive patients have a salt-sensitive hypertension [61] with abnormal renal sodium handling [62], and this is accompanied by progressive renal damage [63]. In a recent study, $73 \%$ of black hypertensives were salt sensitive compared to $56 \%$ of white hypertensives, and renal damage occurred twice as much in the black group. These data indicate that an increase in oxidative stress could be a contributory mechanism in human salt-sensitive hypertension, and oxidative stress may play an important role in the renal damage associated with salt-sensitive hypertension.

\section{Antioxidant Therapy in Humans}

Because of the positive results of vitamin $\mathrm{C}$ or $\mathrm{E}$ treatment in animal experimental studies, several clinical trials have been performed to determine if vitamin treatment can improve cardiovascular disease. Most clinical studies on vitamin $\mathrm{E}$ used doses equal to or less than $400 \mathrm{IU} / \mathrm{day}$, and no significant reduction in cardiovascular risk has been found $[64,65]$. However, when 800 IU/day of vitamin E was used in the CHAOS [66] and SPACE [67] trials, significant decreases in cardiovascular risk occurred. Several studies have shown that there is an inverse relationship between serum vitamin $\mathrm{C}$ and blood pressure in humans. Although variable results have been found, some studies have shown that treatment of hypertensive patients with vitamin $\mathrm{C}$ lowers blood pressure [68].

The reason why vitamins $\mathrm{C}$ and $\mathrm{E}$ improve cardiovascular function in experimental studies and in some human studies but not in others has several possible causes. First, the doses of vitamins $\mathrm{C}$ and $\mathrm{E}$ used in clinical studies may be too low. In a recent 16-week study in hyper- cholesterolemic patients, $400 \mathrm{IU} /$ day of vitamin E did not decrease serum levels of F2-isoprostanes, but doses of vitamin E of 800-3,200 IU/day caused significant reductions in F2-isoprostane levels [69]. A second reason why vitamin $\mathrm{E}$ was ineffective in some clinical studies is that vitamin $\mathrm{E}$ can become a free radical in the body [70], but vitamin $\mathrm{C}$ can convert the pro-oxidant vitamin $\mathrm{E}$ radical back to vitamin $\mathrm{E}$ [70].

In most clinical studies either vitamin $\mathrm{C}$ or $\mathrm{E}$ is used alone, but the combination may be effective and attack free radicals on lipid membranes and in the cytosol. A third reason why vitamin therapy is ineffective in clinical studies is that the patients had preexisting conditions when they entered the studies [64-67]. In studies in our laboratory [29], the combination of vitamins $C$ and E successfully decreased renal oxidative stress, prevented decreases in renal hemodynamics and decreased arterial pressure and renal damage in Dahl S rats on high $\mathrm{Na}$ for 5 weeks.

In patients with chronic renal insufficiency, oral vitamin E supplements reduced the tendency for LDL to be oxidized, which is a key step in the development of atherosclerosis [71]. Vitamin E prevented the oxidative stress during anemia therapy or improved erythropoietin responsiveness, which is often impaired by oxidative stress.

Dialysis membranes often trigger an oxidative stress response, and vitamin E-modified dialysis membranes reduced oxidative stress in one study [72].

\section{Conclusions}

ROS, especially $\mathrm{O}_{\overline{2}}^{\overline{2}}$, is elevated in human hypertension and in patients with ESRD, and their antioxidant capacity is decreased. Salt-sensitive hypertensives have progressive decreases in renal function. In experimental salt-sensitive hypertension, renal $\mathrm{O}_{2}^{\overline{-}}$ production in Dahl $\mathrm{S}$ rats cause progressive increases in renal damage and decreases in renal hemodynamics. Several antioxidant regimens such as vitamins $\mathrm{C}$ and $\mathrm{E}$ and Tempol decrease renal tissue $\mathrm{O}_{\overline{2}}^{\bar{z}}$ production, prevent renal damage, increase renal hemodynamics and decrease blood pressure. These studies provide evidence supporting a hypothesis that ROS play an important role in the progression of salt-sensitive hypertension and the accompanying end-stage renal damage.

\section{Acknowledgements}

This work was supported by NIH grant H1-51971 from the National Heart, Lung and Blood Institute. 


\section{References}

-1 Valderrabano F, Gomez-Campdera F, Jones EH: Hypertension as cause of end-stage renal disease: lessons from international registries. Kidney Int Suppl 1998;68:S60-S66.

-2 Ding Y, Gonick HC, Vaziri ND: Lead promotes hydroxyl radical generation and lipid peroxidation in cultured aortic endothelial cells. Am J Hypertens 2000;13:552-555.

-3 Ding Y, Gonick HC, Vaziri ND, Liang K, Wei L: Lead-induced hypertension. III. Increased hydroxyl radical production. Am J Hypertens 2001;14:169-173.

4 Vaziri ND, Ding Y: Effect of lead on nitric oxide synthase expression in coronary endothelial cells: role of superoxide. Hypertension 2001;37:223-226.

-5 Vaziri ND, Liang K, Ding Y: Increased nitric oxide inactivation by reactive oxygen species in lead-induced hypertension. Kidney Int 1999;56:1492-1498.

-6 Vaziri ND, Wang XQ, Oveisi F, Rad B: Induction of oxidative stress by glutathione depletion causes severe hypertension in normal rats. Hypertension 2000;36:142-146.

7 Zhou XJ, Vaziri ND, Wang XQ, Silva FG, Laszik Z: Nitric oxide synthase expression in hypertension induced by inhibition of glutathione synthase. J Pharmacol Exp Ther 2002;300: 762-767.

8 Welch WJ, Solis G, Chabrashvili T, Aslam S, Chen Y, Wilcox CS: The role of superoxide dismutase on blood pressure regulation during prolonged low dose angiotensin II infusion. Hypertension 2005; in press.

$\checkmark 9$ Chu Y, Iida S, Lund DD, Weiss RM, DiBona GF, Watanabe Y, Faraci FM, Heistad DD: Gene transfer of extracellular superoxide dismutase reduces arterial pressure in spontaneously hypertensive rats: role of heparin-binding domain. Circ Res 2003;92:461-468.

10 Nakamura T, Lozano PR, Ikeda Y, Iwanaga Y, Hinek A, Minamisawa S, Cheng CF, Kobuke K, Dalton N, Takada Y, Tashiro K, Ross JJ, Honjo T, Chien KR: Fibulin-5/DANCE is essential for elastogenesis in vivo. N 2002;415: 171-175.

11 Yanagisawa H, Davis EC, Starcher BC, Ouchi T, Yanagisawa M, Richardson JA, Olson EN: Fibulin-5 is an elastin-binding protein essential for elastic fibre development in vivo. Nature 2002;415:168-171.

12 Lenda DM, Sauls BA, Boegehold MA: Reactive oxygen species may contribute to reduced endothelium-dependent dilation in rats fed high salt. Am J Physiol 2000;279:H7-H14.

13 Liu Y, Rusch NJ, Lombard JH: Loss of endothelium and receptor-mediated dilation in pial arterioles of rats fed a short-term high salt diet. Hypertension 1999;33:686-688.

14 Meng S, Roberts LJ, Cason GW, Curry TS, Manning RD Jr: Superoxide dismutase and oxidative stress in Dahl salt-sensitive and -resistant rats. Am J Physiol 2002;283:R732R738.
15 Gu J-W, Bailey A, Shparago M: Long-term high salt diet causes hypertension and alters renal pro-inflammatory gene expression profiles in Sprague-Dawley rats. FASEB J 2005; 19:A1587.

16 Schnackenberg CG, Wilcox CS: Two-week administration of tempol attenuates both hypertension and renal excretion of 8-Iso prostaglandin F2alpha. Hypertension 1999;33:424-428.

17 Chen X, Touyz RM, Park JB, Schiffrin EL: Antioxidant effects of vitamins $\mathrm{C}$ and $\mathrm{E}$ are associated with altered activation of vascular NADPH oxidase and superoxide dismutase in stroke-prone SHR. Hypertension 2001;38: 606-611.

$\checkmark 18$ Beswick RA, Dorrance AM, Leite R, Webb RC: NADH/NADPH oxidase and enhanced superoxide production in the mineralocorticoid hypertensive rat. Hypertension 2001;38: 1107-1111.

19 Beswick RA, Zhang H, Marable D, Catravas JD, Hill WD, Webb RC: Long-term antioxidant administration attenuates mineralocorticoid hypertension and renal inflammatory response. Hypertension 2001;37:781-786.

20 Meng S, Cason GW, Gannon AW RL, Manning RD Jr: Oxidative stress in Dahl salt-sensitive hypertension. Hypertension 2003;41: 1346-1352.

21 Barton CH, Ni Z, Vaziri ND: Enhanced nitric oxide inactivation in aortic coarctation-induced hypertension. Kidney Int 2001;60: 1083-1087.

22 Vaziri ND: Roles of oxidative stress and antioxidant therapy in chronic kidney disease and hypertension. Curr Opin Nephrol Hypertens 2004;13:93-99.

23 Wilcox CS: Redox regulation of the afferent arteriole and tubuloglomerular feedback. Acta Physiol Scand 2003;179:217-223.

24 Manning RD Jr, Hu L, Reckelhoff JF: Role of nitric oxide in arterial pressure and renal adaptations to long-term changes in sodium intake. Am J Physiol 1997;272:R1162-R1169.

25 Manning RD, Jr., Hu L, Mizelle HL, Montani JP, Norton MW: Cardiovascular responses to long-term blockade of nitric oxide synthesis. Hypertension 1993;22:40-48.

26 Tan DY, Meng S, Manning RD Jr: Role of neuronal nitric oxide synthase in Dahl salt-sensitive hypertension. Hypertension 1999;33: 456-461.

27 Gryglewski RJ, Palmer RMJ, Moncada S: Superoxide anion plays a role in the breakdown of endothelium-derived relaxing factor. $\mathrm{Na}-$ ture 1986;320:454-456.

28 Welch WJ, Tojo A, Wilcox CS: Roles of NO and oxygen radicals in tubuloglomerular feedback in SHR. Am J Physiol 2000;278:F769F776.

29 Tian N, Thrasher KD, Gundy PD, Hughson MD, Manning RD Jr: Antioxidant treatment prevents renal damage and dysfunction and reduces arterial pressure in salt-sensitive hypertension. Hypertension 2005;45:934-939.
30 Makino A, Skelton MM, Zou AP, Cowley AW Jr: Increased renal medullary $\mathrm{H}_{2} \mathrm{O}_{2}$ leads to hypertension. Hypertension 2003;42:25-30.

31 Trolliet MR, Rudd MA, Loscalzo J: Oxidative stress and renal dysfunction in salt-sensitive hypertension. Kidney Blood Press Res 2001; 24:116-123.

32 Chabrashvili T, Kitiyakara C, Blau J, Karber A, Aslam S, Welch WJ, Wilcox CS: Effects of ANG II type 1 and 2 receptors on oxidative stress, renal NADPH oxidase, and SOD expression. Am J Physiol 2003;285:R117R124.

33 Schnackenberg CG, Welch WJ, Wilcox CS: Normalization of blood pressure and renal vascular resistance in SHR with a membrane-permeable superoxide dismutase mimetic: role of nitric oxide. Hypertension 1998;32:59-64.

34 Garvin JL, Ortiz PA: The role of reactive oxygen species in the regulation of tubular function. Acta Physiol Scand 2003;179:225-232.

35 Schnackenberg CG, Welch WJ, Wilcox CS: TP receptor-mediated vasoconstriction in microperfused afferent arterioles: roles of $\mathrm{O}(2)(-)$ and NO. Am J Physiol 2000;279:F302-F308.

36 Zou AP, Li N, Cowley AW Jr: Production and actions of superoxide in the renal medulla. Hypertension 2001;37:547-553.

37 Lounsbury KM, Hu Q, Ziegelstein RC: Calcium signaling and oxidant stress in the vasculature. Free Radic Biol Med 2000;28:13621369.

38 Touyz RM: Oxidative stress and vascular damage in hypertension. Curr Hypertens Rep 2000; 2:98-105.

- 39 Kobori H, Nishiyama A, Abe Y, Navar LG: Enhancement of intrarenal angiotensinogen in Dahl salt-sensitive rats on high salt diet. Hypertension 2003;41:592-597.

40 Park JB, Touyz RM, Chen X, Schiffrin EL: Chronic treatment with a superoxide dismutase mimetic prevents vascular remodeling and progression of hypertension in salt-loaded stroke-prone spontaneously hypertensive rats. Am J Hypertens 2002;15:78-84.

41 Scamps-Latscha B, Drueke T, Witko-Sarsat V: Dialysis-induced oxidative stress: Biological aspects, clinical consequences, and therapy. Semin Dial 2001;14:193- 199.

42 Canaud B, Cristol J, Morena M, Leray-Moragues $\mathrm{H}$, Bosc J, Vaussenat $\mathrm{F}$ : Imbalance of oxidants and antioxidants in haemodialysis patients. Blood Purif 1999;17:99-106.

43 Nguyen AT, Lethias C, Zingraff J, Herbelin A, Naret C, scamps-Latscha B: Hemodialysis membrane-induced activation of phagocyte oxidative metabolism detected in vivo and in vitro within microamounts of whole blood. Kidney Int 1985;28:158-167.

-44 Locatelli F, Canaud B, Eckardt KU, Stenvinkel $\mathrm{P}$, Wanner C, Zoccali C: Oxidative stress in end-stage renal disease: an emerging threat to patient outcome. Nephrol Dial Transplant 2003; 18:1272-1280. 
-45 Vaziri ND, Oveisi F, Ding Y: Role of increased oxygen free radical activity in the pathogenesis of uremic hypertension. Kidney Int 1998;53: 1748-1754.

-46 Vaziri ND, Ni Z, Oveisi F, Liang K, Pandian $\mathrm{R}$ : Enhanced nitric oxide inactivation and protein nitration by reactive oxygen species in renal insufficiency. Hypertension 2002;39:135141.

-47 Hasdan G, Benchetrit S, Rashid G, Green J, Bernheim J, Rathaus M: Endothelial dysfunction and hypertension in 5/6 nephrectomized rats are mediated by vascular superoxide. Kidney Int 2002;61:586-590.

48 Shainkin-Kestenbaum R, Caruso C, Berlyne GM: Reduced superoxide dismutase activity in erythrocytes of dialysis patients: a possible factor in the etiology of uremic anemia. Nephron 1990;55:251-253.

49 Durak I, Akyol O, Basesme E, Canbolat O, Kavutcu M: Reduced erythrocyte defense mechanisms against free radical toxicity in patients with chronic renal failure. Nephron 1994;66: 76-80.

50 Eschbach JW, Adamson JW: Anemia of endstage renal disease (ESRD). Kidney Int 1985; 28:1-5.

-51 Turi S, Nemeth I, Vargha I, Matkovics B, Dobos E: Erythrocyte defense mechanisms against free oxygen radicals in haemodialysed uraemic children. Pediatr Nephrol 1991;5:179-183.

52 Himmelfarb J, Stenvinkel P, Ikizler TA, Hakim RM: The elephant in uremia: oxidant stress as a unifying concept of cardiovascular disease in uremia. Kidney Int 2002;62:15241538 .

53 Swinford RD, Portman RJ: Measurement and treatment of elevated blood pressure in the pediatric patient with chronic kidney disease. Adv Chron Kidney Dis 2004;11:143-161.

54 Buczynski A, Wachowicz B, Kedziora-Kornatowska K, Tkaczewski W, Kedziora J: Changes in antioxidant enzymes activities, aggregability and malonyldialdehyde concentration in blood platelets from patients with coronary heart disease. Atherosclerosis 1993;100:223228 .
\$5 Ceriello A, Giugliano D, Quatraro A, Lefebvre PJ: Anti-oxidants show antihypertensive effect in diabetic and hypertensive subjects. Clin Sci 1991;81:739-742.

$>56$ Galley HF, Thornton J, Howdle PD, Walker BE, Webster NR: Combination oral antioxidant supplementation reduce blood pressure Clin Sci 1997;92:361-365.

>57 Russo C, Olivieri O, Girelli D, Faccini G, Zenari ML, Lombardi S, Corrocher R: Anti-oxidant status and lipid peroxidation in patients with essential hypertension. J Hypertens 1998; 16:1267-1271.

58 Lacy F, O'Connor DT, Schmid-Schonbein GW: Plasma hydrogen peroxide production in hypertensives and normotensive subjects at genetic risk of hypertension. J Hypertens 1998; 16:291-303.

59 Prabha PS, Das UN, Koratkar R, Sagar PS Ramesh G: Free radical generation, lipid peroxidation and essential fatty acids in uncontrolled essential hypertension. Prostaglandins Leukotrienes Essential Fatty Acids 1990;41: 27-33.

60 Kumar DS, Das UN: Are free radicals involved in the pathobiology of human essential hypertension? Free Radic Res Commun 1993;19: 59-66.

61 Weinberger MH: Salt sensitivity of blood pressure in humans. Hypertension 1996;17:481490.

62 Bianchi G, Cusi D, Gatti M, Lupi P, Ferrari P, Parlassina C, Piotti B: A renal abnormality as a possible cause of essential hypertension. Lancet 1979;i:173-177.

63 Lea JP, Nicholas SB: Diabetes mellitus and hypertension: key risk factors for kidney disease. J Natl Med Assoc 2002;94:7S-15S.

64 Marchioli R, Avanzini F, Barzi F, Chieffo C, Di CA, Franzosi MG, Geraci E, Maggioni AP, Marfisi RM, Mininni N, Nicolosi GL, Santini M, Schweiger C, Tavazzi L, Tognoni G, Valagussa F: Assessment of absolute risk of death after myocardial infarction by use of multiplerisk-factor assessment equations: GISSI Prevenzione Mortality Risk Chart. Eur Heart J 2001;22:2085-2103.
65 Hoogwerf BJ, Young JB: The HOPE study: ramipril lowered cardiovascular risk, but vitamin E did not. Cleve Clin J Med 2000;67:287293.

66 Stephens NG, Parsons A, Schofield PM, Kelly F, Cheeseman K, Mitchinson MJ: Randomised controlled trial of vitamin $\mathrm{E}$ in patients with coronary disease: Cambridge Heart Antioxidant Study (CHAOS). Lancet 1996;347:781786.

67 Boaz M, Smetana S, Weinstein T, Matas Z, Gafter U, Iaina A, Knecht A, Weissgarten Y, Brunner D, Fainaru M, Green MS: Secondary prevention with antioxidants of cardiovascular disease in end-stage renal disease (SPACE): randomised placebo-controlled trial. Lancet 2000;356:1213-1218.

68 Duffy SJ, Gokce N, Holbrook M, Huang A, Frei B, Keaney JF Jr, Vita JA: Treatment of hypertension with ascorbic acid. Lancet 1999; 354:2048-2049.

69 Roberts LJ, II, Oates JA, Fazio S, Gross MD, Linton MF, Morrow JD: Alpha tocopherol supplementation reduces plasma F2-isoprostane concentrations in hypercholesterolemic humans only at doses of 800 IU or higher. Free Rad Biol Med 2002;33(Suppl 2):S412.

70 Carr AC, Zhu BZ, Frei B: Potential antiatherogenic mechanisms of ascorbate (vitamin $\mathrm{C}$ ) and alpha-tocopherol (vitamin E). Circ Res 2000;87:349-354.

71 Islam KN, O’Byrne D, Devaraj S, Palmer B, Grundy SM, Jialal I: Alphatocopherol supplementation decreases the oxidative susceptibility of LDL in renal failure patients on dialysis therapy. Atherosclerosis 2000;150:217-224.

72 Miyazaki H, Matsuoka H, Itabe H, Usui M, Ueda S, Okuda S, Imaizumi T: Hemodialysis impairs endothelial function via oxidative stress: effects of vitamin E-coated dialyzer. Circulation 2000;101:1002-1006. 